\title{
Calcium and vitamin D supplementation in pre-eclampsia: Analysis of effectiveness and safety
}

\author{
Yanyu Gao*, Dan Luo, Qiong Wang, Juan Lin \\ Department of Obstetrics and Gynecology, Chengdu Women's and Children's Central Hospital, School of Medicine, University \\ of Electronic Science and Technology of China, Chengdu 611731, China \\ *For correspondence: Email: yanyugao@yahoo.com; Tel/Fax: 0086-028-61866186
}

\begin{abstract}
Purpose: To evaluate the impact of calcium and vitamin $D$ (vit $D$ ) supplementation initiated at early pregnancy in high-risk women on reduction of preeclampsia risk.

Methods: This prospective cohort study involved 492 pregnant women who had experienced preeclampsia or eclampsia in their current pregnancy (high risk) and were either on calcium (1000 mg/day) as well as vit $D$ (400 IU/day) supplementation at early pregnancy or none. All the included pregnant women received standard doses of calcium (1500 mg/day) and vit D (600 IU/day) supplementation post 20 gestation weeks till childbirth. The primary outcome was pre-eclampsia characterized by hypertension as well as proteinuria.

Results: From March 10, 2015 to February 24, 2018, each of the 246 pregnant women were assigned to the calcium/vit $D$ group versus control group with no calcium/vit $D$. In the calcium/vit $D$ group, 26.45 $\%$ developed preeclampsia compared to $32.11 \%$ in control group with a Risk ratio [RR] of 0.82 (95\% confidence interval [CI], 0.62-1.08; $p$ 0.167). No serious adverse events were related to calcium or vit $D$. Conclusion: Calcium/vit $D$ supplementation during early pregnancy did not demonstrate any significant reduction in pre-eclampsia. Large, high-quality studies with higher patient numbers are needed for adequate testing of impact of calcium/vit D on pre-eclampsia.
\end{abstract}

Keywords: Calcium supplement, Pre-eclampsia, Pregnancy, Vitamin D supplement

\begin{abstract}
This is an Open Access article that uses a fund-ing model which does not charge readers or their institutions for access and distributed under the terms of the Creative Commons Attribution License (http://creativecommons.org/licenses/by/4.0) and the Budapest Open Access Initiative (http://www.budapestopenaccessinitiative.org/read), which permit unrestricted use, distribution, and reproduction in any medium, provided the original work is properly credited.

Tropical Journal of Pharmaceutical Research is indexed by Science Citation Index (SciSearch), Scopus, International Pharmaceutical Abstract, Chemical Abstracts, Embase, Index Copernicus, EBSCO, African Index Medicus, JournalSeek, Journal Citation Reports/Science Edition, Directory of Open Access Journals (DOAJ), African Journal Online, Bioline International, Open-J-Gate and Pharmacy Abstracts
\end{abstract}

\section{INTRODUCTION}

Pre-eclampsia, characterized by hypertension and proteinuria appearing post-20 gestation weeks, is a multi-factorial disease in association with perinatal and maternal morbidity and mortality around the world, along with neurological diseases, abnormal renal functioning and liver disorders [1-3]. Nearly 2 $10 \%$ of all pregnancies are complicated by pre- eclampsia and this rate is greater in lower resource settings [3]. Prior studies demonstrated that pre-eclampsia might lead to increased prevalence of risk-factors of cardiovascular diseases, including insulin metabolism impairment, metabolic syndrome, endothelial dysfunction, microalbuminuria, oxidative stress and inflammatory factors $[2,4]$. 
In a cross-sectional study in 29 countries of Asia, Africa, Middle East, and the Latin America, preeclampsia or eclampsia was noted in nearly $25.9 \%$ of pregnant women with serious maternal outcomes (like near miss or maternal death), with direct causative effect in $20 \%$ of maternal deaths reported [5]. Hence, maternal morbidity and mortality from pre-eclampsia/eclampsia is of priority worldwide.

Prior studies showed calcium and vitamin D deficiency amid pregnancy might be independent risk factors for pre-eclampsia [6,7]. A study conducted by Haugen et al [8] demonstrated a $27 \%$ pre-eclampsia risk reduction in women on 10 - $15 \mu /$ day vitamin $D$ supplements in comparison to women on no supplements. Another study showed significant pre-eclampsia risk reduction with calcium supplements $((\geq 1$ g/day) in pregnant women especially on low calcium diets [9]. Such a role of vit D and calcium in preeclampsia was supported in a recent systematic review [10]. These discoveries brought about the speculation that early vit $D$ or calcium supplementation could be beneficial in reducing preeclampsia risk.

As per our knowledge, no study that assessed effect of calcium and vit $D$ supplementation at early pregnancy on pre-eclampsia was conducted. This prospective study goal is to evaluate the impact of calcium and vit $D$ supplementation initiated at early pregnancy in high-risk women on preeclampsia risk reduction.

\section{METHODS}

\section{Ethical approval and consent}

This prospective cohort study was performed at the antenatal clinic of the Department of Obstetrics and Gynecology of the institute from March 10, 2015 to February 24, 2018. The hospital's review board approval was received (approval no. 2015CWCH1038). Patient confidentiality was strictly maintained. The guidelines set forth in the Helsinki Declaration [11] was followed. Informed consent was taken from all the participants. The study adhered to the research laws of China.

\section{Study cohorts}

The study population included pregnant women older than 18 years old, with pre-eclampsia or eclampsia in their current pregnancy (high risk) and were on calcium (1000 mg/day) as well as vit D (400 IU/day) supplementation at early pregnancy (8 weeks of gestation). The control group included high-risk pregnant women with no calcium or vit D supplementation at early pregnancy (until 20 gestation weeks). The pregnant women in our hospital are usually advised to take calcium and vit D supplementation at doses of $1500 \mathrm{mg} /$ day and $600 \mathrm{IU} /$ day respectively. Post 20 gestation weeks and all the included pregnant women followed the same till childbirth. The doses are as per recommendations by World Health Organization (WHO) [12] and Institute of Medicine (IOM) [13]. Participants were advised to take no extra calcium supplementation. Paracetamol was recommended in case of analgesics, if needed whereas non-calcium-based antacids in case of antacids.

\section{Data collection}

Clinical as well as demographic data of included pregnant women were noted from the medical records (charts review). The exclusion criteria included multiple pregnancies, fetal malformations, polyhydramnios, diabetes, renal disease, chronic hypertension, urolithiasis, cardiovascular disease, or $140 / 90 \mathrm{mmHg}$ or higher blood pressure at the first visit.

\section{Outcome measurements}

The primary outcome was pre-eclampsia characterized by hypertension as well as proteinuria. The secondary outcomes were a composite.

\section{Statistical analyses}

Values are denoted as percentages in case of categorical variables, whereas means and standard deviations in case of continuous variables. Risk ratios (RR) with $95 \%$ confidence interval $(\mathrm{Cl})$ was used to compare categorical variables that was performed using Medcalc for windows, version 15.0 (MedCalc Software, Ostend, Belgium). All data were analyzed using IBM SPSS Statistics for Windows (version 21.0; IBM Corp., Armonk, NY, USA). $P<0.05$ was considered statistically significant.

\section{RESULTS}

In the present study 492 pregnant women were enrolled; 246 women each were allocated to the calcium/vit D group and control group with no calcium/vit $D$. The clinical and demographic data of the participants were recorded and compared, which were comparable between the groups, including age, systolic/diastolic blood pressure, body mass index, and prior medical history (all $p$ $>0.05$; Table 1). 
Table 1: Clinical/demographic characteristics

\begin{tabular}{|c|c|c|}
\hline Characteristic & $\begin{array}{c}\text { Group A (calcium + vit D, } \\
n=246)\end{array}$ & $\begin{array}{c}\text { Group B (no calcium or Vit } \\
\qquad, n=246)\end{array}$ \\
\hline Maternal age (yrs) & $30.22 \pm 4.98$ & $29.84 \pm 4.62$ \\
\hline Body mass index (BMI; kg/m²) & $29.32 \pm 6.6$ & $29.41 \pm 6.4$ \\
\hline $\mathrm{BMI}>30$ & $108(43.9 \%)$ & $112(45.53 \%)$ \\
\hline \multicolumn{3}{|l|}{ Baseline blood pressure, $\mathrm{mmHg}$} \\
\hline Systolic & $125 \pm 18.13$ & $125.32 \pm 19.24$ \\
\hline Diastolic & $82.2 \pm 11.62$ & $82.9 \pm 12.81$ \\
\hline \multicolumn{3}{|l|}{ Prior medical history } \\
\hline Severe pre-eclampsia* & $205(83.33 \%)$ & $216(87.8 \%)$ \\
\hline Eclampsia & $54(21.95 \%)$ & $61(24.48 \%)$ \\
\hline HELLP syndrome & $37(15.04 \%)$ & $52(21.14 \%)$ \\
\hline Live birth & $118(47.97 \%)$ & $111(45.12 \%)$ \\
\hline
\end{tabular}

Table 2: Primary and secondary outcomes data

\begin{tabular}{|c|c|c|c|c|}
\hline Outcome & $\begin{array}{c}\text { Group A } \\
\text { (calcium plus } \\
\text { vit } \mathrm{D}, \% \text { ) }\end{array}$ & $\begin{array}{c}\text { Group B (no } \\
\text { calcium or vit D, } \\
\% \text { ) }\end{array}$ & Risk ratio $(\mathrm{Cl})$ & $P$-value \\
\hline \multicolumn{5}{|l|}{ Primary outcome } \\
\hline Pre-eclampsia & $65 / 246(26.42)$ & $79 / 246(32.11)$ & $0.82(0.62-1.08)$ & 0.167 \\
\hline \multicolumn{5}{|l|}{ Secondary outcome } \\
\hline $\begin{array}{l}\text { Pre-eclampsia and/or pregnancy loss } \\
\text { at any gestation }\end{array}$ & $89 / 246(36.18)$ & $108 / 246(43.90)$ & $0.82(0.66-1.02)$ & 0.082 \\
\hline Gestational proteinuria & $72 / 246$ (29.27) & $85 / 246$ (34.55) & $0.85(0.65-1.09)$ & 0.209 \\
\hline Gestational hypertension & $169 / 246(68.7)$ & $181 / 246(73.58)$ & $0.93(0.83-1.05)$ & 0.233 \\
\hline Severe gestational hypertension & $83 / 246(33.74)$ & $90 / 246(36.59)$ & $0.92(0.73-1.17)$ & 0.509 \\
\hline Early onset preeclampsia* & $39 / 246(15.85)$ & $40 / 246(16.26)$ & $0.98(0.65-1.46)$ & 0.902 \\
\hline Severe preeclampsia & $54 / 246(21.95)$ & $61 / 246(24.80)$ & $0.89(0.64-1.22)$ & 0.456 \\
\hline Increased Uric acid values & $19 / 26(73.08)$ & $17 / 24(70.83)$ & $1.03(0.73-1.46)$ & 0.86 \\
\hline Liver failure & $9 / 51(17.65)$ & $8 / 62(12.9)$ & $1.37(0.57-3.29)$ & 0.484 \\
\hline Renal failure $^{* *}$ & $7 / 51(13.73)$ & $6 / 62(9.68)$ & $1.42(0.51-3.96)$ & 0.504 \\
\hline Moderately severe thrombocytopenia & $14 / 61(22.95)$ & $13 / 76(17.11)$ & $1.34(0.68-2.64)$ & 0.394 \\
\hline Eclampsia§ & $6 / 246(2.44)$ & $10 / 246(4.07)$ & $0.60(0.22-1.63)$ & 0.315 \\
\hline HELLP syndrome & $11 / 65(16.92)$ & $9 / 79(11.39)$ & $1.49(0.66-3.36)$ & 0.342 \\
\hline ICU admission $>24 \mathrm{~h}$ & $3 / 246(1.22)$ & $4 / 246(1.63)$ & $0.75(0.17-3.32)$ & 0.705 \\
\hline Placental abruption & $11 / 246(4.47)$ & $8 / 246(3.25)$ & $1.38(0.56-3.36)$ & 0.485 \\
\hline Maternal death & 0 & 0 & - & - \\
\hline Caesarean section & $152 / 246(61.79)$ & $136 / 246(55.28)$ & $1.12(0.96-1.29)$ & 0.144 \\
\hline Early preterm birth ${ }^{*}$ & $48 / 246(19.51)$ & $59 / 246(23.98)$ & $0.81(0.58-1.14)$ & 0.23 \\
\hline Preterm birth ${ }^{* * *}(<37$ weeks' & $104 / 246(42.28)$ & $112 / 246(45.53)$ & $0.93(0.76-1.13)$ & 0.468 \\
\hline gestation) & $56 / 217(25.81)$ & $61 / 204(29.90)$ & $0.86(0.63-1.17)$ & 0.349 \\
\hline Birthweight $<2500 \mathrm{~g}$ & $8 / 217(3.69)$ & $14 / 204(6.86)$ & $0.54(0.23-1.25)$ & 0.15 \\
\hline Apgar score $<7$ at $5 \mathrm{~min}$ & $46 / 217(21.2)$ & $39 / 204(19.12)$ & $1.10(0.76-1.62)$ & 0.596 \\
\hline Neonatal ICU admission/Perinatal & $27 / 246(10.98)$ & $32 / 246(13.01)$ & $0.84(0.52-1.36)$ & 0.489 \\
\hline death & $97 / 246(39.43)$ & $99 / 246(40.24)$ & $0.98(0.79-1.22)$ & 0.854 \\
\hline Stillbirth & $58 / 246(23.58)$ & $62 / 246(25.20)$ & $0.94(0.69-1.28)$ & 0.674 \\
\hline \multicolumn{5}{|l|}{ Severe pre-eclampsia complications } \\
\hline \multicolumn{5}{|l|}{ index ${ }^{\delta}$} \\
\hline \multicolumn{5}{|l|}{$\begin{array}{l}\text { Severe maternal morbidity and } \\
\text { mortality index }{ }^{\ddagger}\end{array}$} \\
\hline \multicolumn{5}{|c|}{$\begin{array}{l}\mathrm{Cl}=95 \% \text { confidence interval; HELLP=hemolysis, elevated liver enzymes, as well as low platelet count; } \\
\text { ICU=intensive care unit; }{ }^{*}<32 \text { weeks'; gestation; }{ }^{* *} \text { Creatinine }>120 \mathrm{mmol} / \mathrm{L} ;{ }^{* * *}<37 \text { weeks' gestation; } \S A l l \\
\text { patients with eclampsia had pre-eclampsia too; } \delta \text { Severe pre-eclampsia complications index constitutes at least } \\
\text { one of the following: eclampsia, early-onset pre-eclampsia, severe pre-eclampsia, HELLP syndrome, placental } \\
\text { abruption, or severe gestational hypertension; } \ddagger S e v e r e \text { maternal morbidity and mortality index constitutes at least } \\
\text { one of the following: ICU or special care unit admission, eclampsia, HELLP syndrome, placental abruption, renal } \\
\text { failure, or death }\end{array}$} \\
\hline
\end{tabular}


The results of primary as well as secondary outcomes were presented in Table 2. In case of primary outcome, participants in the calcium/vit $D$ group showed lower preeclampsia prevalence (65/246; $26.42 \%)$ when compared to control group $(79 / 246 ; 32.11 \%)$ with $18 \%$ reduction (RR $0.82[\mathrm{Cl} 0.62-1.08] ; p=0.167)$, which is insignificant. None of the differences in secondary outcomes between the groups were significant. The prevalence of pre-eclampsia and/or pregnancy loss at any gestation, was $36.18 \%$ in the calcium/vit D group and $43.9 \%$ in the control group (RR 0.82 [Cl 0.66-1.02]), with borderline significance. The differences in the composite outcomes (severe pre-eclampsia complications index as well as severe maternal morbidity and mortality index) were not significant. Serious adverse events from the records were noted. None of them were related to the calcium or vit $D$.

\section{DISCUSSION}

This prospective study did not demonstrate any significant pre-eclampsia reduction with calcium/vit D supplementation amid early pregnancy. This study is not like the earlier studies on either calcium or vit D supplementation for pre-eclampsia prevention. In this study, an attempt was made to identify the impact of calcium and vit $D$ at early pregnancy (that is amid defective placentation which is presumed to is thought to start off the preeclampsia pathway) on pre-eclampsia development later in pregnancy in spite of higher doses of calcium and/or Vit D supplementation continued from 20 gestation weeks till birth, as suggested by WHO [14].

The secondary outcome of pre-eclampsia and/or loss of pregnancy at any gestation deserves discussion since loss of pregnancy may be associated with pre-eclampsia. This result may overcome preeclampsia result confounding by early impact of calcium/vit $D$ on loss of pregnancy and could be a good marker of general impact of calcium/vit D supplementation. With calcium/vit D supplements, $18 \%$ risk reduction was noted in the above-mentioned secondary outcome.

Meaningful statistical analysis was not possible for serious outcomes as they are too little in number. Such a lower prevalence of serious outcomes is not out of the ordinary as all the included participants were on higher doses of calcium and vit D supplementation from 20 gestation weeks, which are known to decrease the rate of severe pre-eclampsia complications. In addition, the decreased rate of poor outcomes might also be due to higher quality of care given to the pregnant women due to study participation as showed by the way that, in spite of there being a higher prior pre-eclampsia prevalence, the eclampsia prevalence was found to be lower $(2.44 \%$ in calcium/vit D group; $4.07 \%$ in control group).

As per our knowledge, this study is the first to assess the effect of calcium and vit $D$ supplementation at early pregnancy on preeclampsia. One study [15] on calcium supplement usage in early pregnancy was reported where antioxidant as well as calcium supplementation initiated at $8-12$ gestation weeks reduced prevalence of pre-eclampsia (6.8 vs $29 \% ; p=0.043$ ) in comparison to placebo group. The outcomes are indicative of the role of calcium in reducing.

\section{Limitations of the study}

The results of this study might not be generalizable as it is a single center study with a limited number of patients involved. There is a chance of information bias as well as recall bias since only a few patients were asked to supply their data when such information was not available in their medical records.

\section{CONCLUSION}

Calcium/vit D supplementation amid early pregnancy did not demonstrate any significant reduction pre-eclampsia. The present study results suggest that a large, high-quality studies with higher patient numbers are needed for adequate testing of impact of calcium/vit $D$ on pre-eclampsia.

\section{DECLARATIONS}

\section{Conflict of interest}

No conflict of interest is associated with this work.

\section{Contribution of authors}

We declare that this work was done by the authors named in this article and all liabilities pertaining to claims relating to the content of this article will be borne by the authors. All the authors contributed equally to this work.

\section{Open Access}

This is an Open Access article that uses a funding model which does not charge readers or their 
institutions for access and distributed under the terms of the Creative Commons Attribution License (http://creativecommons.org/licenses/by/ 4.0) and the Budapest Open Access Initiative (http://www.budapestopenaccessinitiative.org/rea d), which permit unrestricted use, distribution, and reproduction in any medium, provided the original work is properly credited.

\section{REFERENCES}

1. ACOG Committee on Practice Bulletins--Obstetrics. ACOG practice bulletin. Diagnosis and management of preeclampsia and eclampsia. Number 33, January 2002. Obstet Gynecol 2002; 99(1): 159-167.

2. Hofmeyr GJ, Betrán AP, Singata-Madliki M, Cormick $G$, Munjanja SP, Fawcus S, Mose S, Hall D, Ciganda A, Seuc $A H$ et al. Calcium and Pre-eclampsia Study Group. Pre-pregnancy and early pregnancy calcium supplementation among women at high risk of preeclampsia: a multicentre, double-blind, randomised, placebo-controlled trial. Lancet 2019; 393(10169): 330339.

3. Samimi $M$, Kashi $M$, Foroozanfard $F$, Karamali $M$, Bahmani F, Asemi Z, Hamidian $Y$, Talari HR, Esmaillzadeh $A$. The effects of vitamin $D$ plus calcium supplementation on metabolic profiles, biomarkers of inflammation, oxidative stress and pregnancy outcomes in pregnant women at risk for pre-eclampsia. J Hum Nutr Diet 2016; 29(4): 505-515.

4. Aykas F, Solak Y, Erden A, Bulut K, Dogan S, Sarli B, Acmaz G, Afsar B, Siriopol D, Covic A et al. Persistence of cardiovascular risk factors in women with previous preeclampsia: a long-term follow-up study. J Investig Med 2015; 63: 641-645.

5. Souza JP, Gülmezoglu AM, Vogel J, Carroli G, Lumbiganon $P$, Qureshi $Z$, Costa MJ, Fawole $B$, Mugerwa $Y$, Nafiou I et al. Moving beyond essential interventions for reduction of maternal mortality (the WHO Multi-country Survey on Maternal and Newborn Health): a cross-sectional study. Lancet 2013; 381: 1747-55.

6. Achkar M, Dodds L, Giguère Y, Forest JC, Armson BA, Woolcott C, Agellon S, Spencer A, Weiler HA. Vitamin D status in early pregnancy and risk of preeclampsia. Am J Obstet Gynecol 2015; 212: 511.e1-e7.

7. Ephraim RK, Osakunor DN, Denkyira SW, Eshun $H$, Amoah S, Anto EO. Serum calcium and magnesium levels in women presenting with pre-eclampsia and pregnancy-induced hypertension: a case-control study in the Cape Coast metropolis. Ghana. BMC Pregnancy Childbirth 2014; 14: 390.

8. Haugen $M$, Brantsaeter AL, Trogstad L, Alexander J, Roth C, Magnus $P$, Meltzer HM. Vitamin $D$ supplementation and reduced risk of preeclampsia in nulliparous women. Epidemiology 2009; 20(5): 720-726.

9. Hofmeyr GJ, Lawrie TA, Atallah AN, Duley L, Torloni MR. Calcium supplementation during pregnancy for preventing hypertensive disorders and related problems. Cochrane Database Syst Rev 2014; 6: CD001059.

10. Khaing W, Vallibhakara SA, Tantrakul V, Vallibhakara O, Rattanasiri S, McEvoy M, Attia J, Thakkinstian A. Calcium and Vitamin D Supplementation for Prevention of Preeclampsia: A Systematic Review and Network Meta-Analysis. Nutrients 2017; 9(10): 1141.

11. World Medical Association. Declaration of Helsinki, Ethical Principles for Medical Research involving human subjects. Available from: http:// https://www.wma.net/wpcontent/uploads/2016/11/DoH-Oct2008.pdf. Accessed February 15, 2020.

12. WHO. Guideline: calcium supplementation in pregnant women. Geneva: World Health Organization, 2013. http://apps. who.int/iris/bitstream/10665/85120/1/978924 1505376_eng.pdf. (accessed Feb 12, 2020).

13. Del Valle $H B$, Yaktine AL, Taylor CL, Ross AC, eds. Dietary Reference Intakes for Calcium and Vitamin $D$. Washington, DC: National Academies Press; 2011.

14. Newmark HL, Heaney RP, and Lachance PA. Should calcium and vitamin $D$ be added to the current enrichment program for cereal-grain products. Am J Clin Nutr 2004; 80: 264-70.

15. Rumiris $D$, Purwosunu $Y$, Wibowo $N$, Farina $A$, Sekizawa A. Lower rate of preeclampsia after antioxidant supplementation in pregnant women with low antioxidant status. Hypertens Pregnancy 2006; 25: 24153.

16. Hofmeyr GJ, Manyame S. Calcium supplementation commencing before or early in pregnancy, or food fortification with calcium, for preventing hypertensive disorders of pregnancy. Cochrane Database Syst Rev 2017; 9: CD011192.

17. Liu X, Wang X, Tian Y, Yang Z, Lin L, Lin Q, Zhang Z, Li $L$. Reduced maternal calcium intake through nutrition and supplementation is associated with adverse conditions for both the women and their infants in a Chinese population. Medicine (Baltimore) 2017; 96(18): e6609.

18. Yu L, Guo Y, Ke HJ, He YS, Che D, Wu JL. Vitamin D Status in Pregnant Women in Southern China and Risk of Preterm Birth: A Large-Scale Retrospective Cohort Study. Med Sci Monit 2019; 25: 7755-7762. 